\title{
Influence of neutropenia on mortality of critically ill cancer patients: results of a meta-analysis on individual data
}

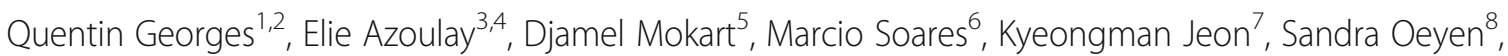
Chin Kook Rhee ${ }^{9}$, Pascale Gruber ${ }^{10}$, Marlies Ostermann ${ }^{11}$, Quentin A. Hill ${ }^{12}$, Pieter Depuydt ${ }^{8}$, Christelle Ferra ${ }^{13}$, Anne-Claire Toffart ${ }^{14}$, Peter Schellongowski ${ }^{15}$, Alice Müller ${ }^{16}$, Virginie Lemiale ${ }^{3}$, Fabien Tinquaut ${ }^{17}$, Aurélie Bourmaud ${ }^{17}$ and Michaël Darmon ${ }^{1,2,3,4,18^{*}}$

\begin{abstract}
Background: The study objective was to assess the influence of neutropenia on outcome of critically ill cancer patients by meta-analysis of individual data. Secondary objectives were to assess the influence of neutropenia on outcome of critically ill patients in prespecified subgroups (according to underlying tumor, period of admission, need for mechanical ventilation and use of granulocyte colony stimulating factor (G-CSF)).

Methods: Data sources were PubMed and the Cochrane database. Study selection included articles focusing on critically ill cancer patients published in English and studies in humans from May 2005 to May 2015. For study selection, the study eligibility was assessed by two investigators. Individual data from selected studies were obtained from corresponding authors.

Results: Overall, 114 studies were identified and authors of 30 studies (26.3\% of selected studies) agreed to participate in this study. Of the 7515 included patients, three were excluded due to a missing major variable (neutropenia or mortality) leading to analysis of 7512 patients, including 1702 neutropenic patients (22.6\%). After adjustment for confounders, and taking study effect into account, neutropenia was independently associated with mortality (OR 1.41; $95 \% \mathrm{Cl} 1.23-1.62 ; P=0.03)$. When analyzed separately, neither admission period, underlying malignancy nor need for mechanical ventilation modified the prognostic influence of neutropenia on outcome. However, among patients for whom data on G-CSF administration were available $(n=1949 ; 25.9 \%)$, neutropenia was no longer associated with outcome in patients receiving G-CSF (OR 1.03; 95\% Cl 0.70-1.51; $P=0.90)$.
\end{abstract}

Conclusion: Among 7512 critically ill cancer patients included in this systematic review, neutropenia was independently associated with poor outcome despite a meaningful survival. Neutropenia was no longer significantly associated with outcome in patients treated by G-CSF, which may suggest a beneficial effect of G-CSF in neutropenic critically ill cancer patients.

Systematic review registration: PROSPERO CRD42015026347. Date of registration: Sept 182015

Keywords: Prognosis, Outcomes, Hematologic, Neoplasms, Intensive care units, Mechanical ventilation, Neutropenia

\footnotetext{
* Correspondence: michael.darmon@aphp.fr

${ }^{1}$ Medical-Surgical ICU, Saint-Etienne University Hospital, Avenue Albert

Raimond, 42270 Saint-Priest-en-Jarez, France

${ }^{2} J a c q u e s$ Lisfranc Saint-Etienne Medical School, Jean Monnet University,

Saint-Priest-en-Jarez, France

Full list of author information is available at the end of the article
}

(c) The Author(s). 2018 Open Access This article is distributed under the terms of the Creative Commons Attribution 4.0 International License (http://creativecommons.org/licenses/by/4.0/), which permits unrestricted use, distribution, and

reproduction in any medium, provided you give appropriate credit to the original author(s) and the source, provide a link to the Creative Commons license, and indicate if changes were made. The Creative Commons Public Domain Dedication waiver (http://creativecommons.org/publicdomain/zero/1.0/) applies to the data made available in this article, unless otherwise stated. 


\section{Background}

Cancer is a leading cause of death in North America and Europe [1, 2], and cancer patients are at high risk for life-threatening complications as a result of infection [3], toxicity of intensive treatments [4] or targeted therapies [5], warranting admission to the intensive care unit (ICU). Despite evidence that ICU mortality rates have declined significantly over the last two decades $[6,7]$, and although the number and extent of comorbidities, pre-existing performance status along with organ failure have been demonstrated to be the main prognostic factors in this setting [8-10], intensivists may be reluctant to admit specific cancer patient populations such as neutropenic patients.

Although meaningful survival has been described in neutropenic patients $[11,12]$, the prognostic impact of neutropenia remains controversial. Neutropenia remains a common side effect of cancer chemotherapy and, although transient, may lead to immune dysfunction. Clinical consequences of neutropenia are well known and include occurrence of sepsis or acute respiratory failure [13], worsening of respiratory status during neutropenia recovery [14] and need for specific management [15]. In contrast to critically ill cancer patients, neutropenia was found to be an independent risk factor of poor outcome in the general ICU population [16]. The lack of prognostic impact in critically ill cancer patients may thus reflect an absence of statistical power or the influence of coexistent mechanisms of immune deficiency in these patients. In a previous systematic review performed on aggregated data, neutropenia was associated with an increase in relative risk of death of $10 \%$ in critically ill cancer patients [17]. With regards to the limited number of studies reporting an adjusted impact of neutropenia, however, this preliminary study failed to demonstrate an independent impact of neutropenia on outcome [17].

The aim of this study was to assess influence of neutropenia on outcome of critically ill cancer patients by a meta-analysis of individual data. Secondary objectives were to assess influence of neutropenia on outcome of critically ill patients in prespecified subgroups (according to underlying tumor, period of admission, need for mechanical ventilation and use of granulocyte colony stimulating factor (G-CSF)).

\section{Methods}

This systematic review and meta-analysis of individual data was performed according to the guidelines on Meta-analysis of Observational Studies in Epidemiology [18]. This study was registered on the PROSPERO database (CRD42015026347). This study was a preplanned follow-up study of an initial meta-analysis on aggregated data [17].

\section{Study outcome and definitions}

The aim of this meta-analysis of individual data was to determine the prognostic impact of neutropenia on outcome of critically ill cancer patients.
Neutropenia was defined as a neutrophil count (or if missing as a white blood cell count) lower than $1 \mathrm{G} / \mathrm{L}$ (stage 3 or more according to Common Terminology Criteria for Adverse Events version 4.03) (https://evs.nci.nih.gov/ftp1/CTCAE/CTCAE_4.03/CTCAE_4.03_2010-06-14_ QuickReference_5x7.pdf).

Outcome was defined as hospital mortality or day-28 mortality if the former was unavailable (Table 1). Choice of this outcome variable was driven by availability of data precluding use of longer follow-up such as day 90. Although ICU mortality was available for most of the reported studies, this variable is more prone to be influenced by the discharge policy in participating centers and a longer follow-up period was preferred [19].

\section{Search strategy and eligibility assessment}

First, public-domain databases including PubMed and the Cochrane database were searched using Exploded Medical Subject Headings and the appropriate corresponding keywords: "NEOPLASM" OR "MALIGNANCY" OR "CANCER" AND "INTENSIVE CARE UNIT" OR "ICU". The research was restricted to publications in English and studies concerning humans from May 2005 to May 2015. Studies published before 2005 not included to limit heterogeneity across studied populations that may have arisen with regard to prognostic change of both critically ill and critically ill cancer patients [20, 21]. Abstracts were carefully checked and studies focusing on children or patients aged younger than 18 years old, case reports and studies failing to focus on critically ill patients were excluded.

All remaining references were then downloaded for consolidation, elimination of duplicates and further analysis. Four investigators (Marie Bouteloup, Sophie Perinel, DM, MD) independently determined the eligibility of all studies identified in the initial research. Last, studies with explicit redundancies were only included once (for this study, redundancies were assessed by QG and MD).

Each of the included studies obtained approval of a local or a national ethic committee in accordance with local legislation. Patients or their next of kin consented to participate or were informed of the included study and did not oppose participation according to local legislation. With regard to its retrospective design and lack of change of the primary outcome variable, the need for additional ethic committee approval was waived according to French Law.

Patients were not involved in the included studies' design. The primary outcome measure was defined according to its clinical relevance for both patients and carers. Health care providers were involved in patient recruitment. Last, the patients and physicians involved in the analyzed studies are thanked in Acknowledgements. 
Table 1 Included studies' characteristics

\begin{tabular}{|c|c|c|c|c|c|c|c|c|}
\hline Author, year & $\begin{array}{l}\text { Follow- } \\
\text { up }\end{array}$ & $n$ & $\begin{array}{l}\text { SAPS ॥ } \\
\text { equivalent }\end{array}$ & $\begin{array}{l}\text { Prospective } \\
\text { study }\end{array}$ & $\begin{array}{l}\text { Number of } \\
\text { centers }\end{array}$ & $\begin{array}{l}\text { Solid tumors } \\
(\%)\end{array}$ & $\begin{array}{l}\text { Mortality } \\
(\%)\end{array}$ & $\begin{array}{l}\text { Risk of } \\
\text { bias }\end{array}$ \\
\hline Canet et al., 2013 [34] & Hospital & 200 & $34(24-50)$ & Yes & 1 & 0 & 30.0 & 7 \\
\hline Depuydt et al., 2010 [33] & Hospital & 137 & $25(20-30)$ & No & 1 & 2.2 & 62.8 & 7 \\
\hline Bird et al., 2012 [27] & Hospital & 199 & $21(17-25)$ & Yes & 1 & 0 & 54.3 & 5 \\
\hline Hill et al., 2012 [28] & Hospital & 147 & $62(48-80)$ & No & 5 & 0 & 73.5 & 5 \\
\hline Müller et al., 2013 [35] & Hospital & 34 & $57(31-97.75)$ & No & 1 & 100 & 44.1 & 5 \\
\hline Namendys-Silva et al., 2012 [30] & Hospital & 184 & $40(31-51)$ & Yes & 1 & 30.4 & 58.2 & 6 \\
\hline Yeo et al., 2012 [48] & Hospital & 227 & $54(37-71)$ & No & 1 & 0 & 89.9 & 7 \\
\hline Oeyen et al., 2013 [36] & Hospital & 483 & $34(22-48)$ & Yes & 1 & 82.4 & 16.4 & 6 \\
\hline Ferra et al., 2007 [37] & Hospital & 100 & $60(44.25-71)$ & Yes & 1 & 0 & 64.0 & 5 \\
\hline Soares et al., 2006 [20] & Hospital & 309 & $56(45-68)$ & Yes & 1 & 24.6 & 64.1 & 7 \\
\hline Soares et al., 2007 (Chest) [38] & Hospital & 143 & $44(32.5-57)$ & Yes & 2 & 100 & 58.7 & 6 \\
\hline $\begin{array}{l}\text { Soares et al., } 2007 \text { (Intensive Care } \\
\text { Med) [44] }\end{array}$ & Hospital & 121 & $47(37-62)$ & Yes & 1 & 0 & 56.2 & 6 \\
\hline Soares et al., 2008 [32] & Hospital & 1090 & $44(32-56.75)$ & Yes & 1 & 81.8 & 51.2 & 7 \\
\hline Soares et al., 2010 [25] & Hospital & 717 & $29(19-42)$ & Yes & 28 & 93 & 30.4 & 7 \\
\hline Souza-Dantas et al., 2011 [45] & Hospital & 188 & $62(48.75-73)$ & No & 1 & 31.9 & 75.5 & 7 \\
\hline Soares et al., 2014 (46) & Hospital & 449 & $44(33-55)$ & Yes & 22 & 100 & 38.8 & 5 \\
\hline Song et al., 2011 [26] & Hospital & 62 & $41(25-51)$ & No & 1 & 21 & 69.4 & 6 \\
\hline Yoo et al., 2013 [42] & Hospital & 214 & $44(35-59)$ & No & 1 & 46.3 & 49.1 & 7 \\
\hline Lee et al., 2015 [43] & Hospital & 525 & $61.5(51-70)$ & Yes & 1 & 40.2 & 56.0 & 7 \\
\hline Mokart et al., 2007 [21] & 28 days & 51 & $49(35.5-70.25)$ & Yes & 1 & 21.6 & 43.1 & 5 \\
\hline Mokart et al., 2012 [47] & Hospital & 111 & $45(33-55)$ & Yes & 1 & 21.6 & 40.5 & 6 \\
\hline Adda et al., 2008 [41] & Hospital & 99 & $49(39.5-57)$ & No & 1 & 0 & 61.6 & 6 \\
\hline Burghi et al., 2011 [40] & 28 days & 59 & NA & No & 1 & 0 & 72.9 & 7 \\
\hline Legriel et al., 2010 [23] & Hospital & 101 & $55(42-67)$ & No & 1 & 29.7 & 44.6 & 5 \\
\hline Xhaard et al., 2013 [29] & Hospital & 62 & NA & No & 1 & 0 & 41.9 & 5 \\
\hline Azoulay et al., 2008 [22] & Hospital & 148 & NA & Yes & 1 & 12.8 & 55.4 & 6 \\
\hline Azoulay et al., 2013 [8] & 28 days & 1011 & $29(23-39)$ & Yes & 17 & 0 & 38.2 & 7 \\
\hline McGrath et al., 2010 [24] & Hospital & 185 & $39(26-47)$ & No & 1 & 37.8 & 31.4 & 5 \\
\hline Wohlfarth et al., 2014 [31] & Hospital & 56 & $50(39-60.5)$ & No & 1 & 14.3 & 41.1 & 5 \\
\hline Toffart et al., 2011) [39] & Hospital & 103 & $44(33-57)$ & No & 3 & 100 & 31.1 & 7 \\
\hline
\end{tabular}

SAPS Simplified Acute Physiology Score

\section{Data and quality assessment}

Investigators of selected publications were contacted twice and invited to participate in this study. Authors who agreed to participate were asked to send a file containing individual data including: age, gender, year of admission, underlying malignancy (solid tumor vs hematological malignancy), history of allogeneic stem cell transplantation, severity score, need for organ support (invasive mechanical ventilation, vasopressor use, renal replacement therapy), neutropenia during ICU stay, neutropenia duration, use of granulocyte colony stimulating factor (G-CSF), follow-up and outcome.
To enable study comparison, we transformed illness severity scores (Acute Physiology and Chronic Health Evaluation (APACHE) II and APACHE III) into the equivalent Simplified Acute Physiology Score (SAPS) II, using a previously described methodology [22]. When neither the APACHE II score nor the APACHE III score was available, the available severity score was transformed into the SAPS II according to the estimated odds of dying during the ICU stay.

Risk of bias of included studies was assessed using the "risk bias in cohort study" tool developed by the Cochrane group (http://methods.cochrane.org/sites/ methods.cochrane.org.bias/files/public/uploads/ 
Tool\%20to\%20Assess\%20Risk\%20of\%20Bias\%20in\%20Co hort\%20Studies.pdf; accessed February 2, 2017).

\section{Statistical analysis}

All quantitative variables were described using medians (quartiles) while qualitative variables were described with their frequencies (percentage). The overall association between mortality and patient characteristics was determined with a one-step meta-analysis approach. Univariate analyses were performed using a logistic regression model with random study effects to obtain odds ratios (ORs) with their two-sided 95\% confidence intervals (CIs) as measures of relative risk. Variables identified as being associated with mortality in univariate analyses, with $P<0.20$, were included in a multivariate logistic regression model with a random study effect. Chi-square heterogeneity tests were used to test for statistical heterogeneity among studies. The $I^{2}$ index (expressing the proportion of variability of the results related to heterogeneity) was reported.

Strata analyses were performed using the statistical plan already described for the following strata: patients with ICU admission after 2007 (median ICU admission period in the studied population), patients with hematological malignancy, patients requiring mechanical ventilation and patients receiving G-CSF.

All effect sizes with $P<0.05$ were considered significant. All analyses were carried out with software $\mathrm{R}$, version 3.2.5. The lme4 and Meta package were used to take into account the random effects and to produce forest plots.

\section{Results}

Our initial search yielded 1528 citations, of which 38 were excluded due to duplication and 706 were excluded as irrelevant for the scope of this review. All abstracts of the remaining 784 records were carefully checked and 131 full-text articles focusing on critically ill cancer patients' prognosis were scrutinized for further evaluation. Seventeen studies were excluded, including 10 studies with redundancies, five studies lacking neutropenic, non-neutropenic patients or major data required for the analysis, and two studies including only palliative patients. Among the remaining 114 studies, authors of 30 studies $(26.3 \%$ of selected studies) agreed to participate in this study, leading to a dataset of 7515 patients, including 1702 neutropenic patients (22.6\%) (Fig. 1) [8, 23-51].

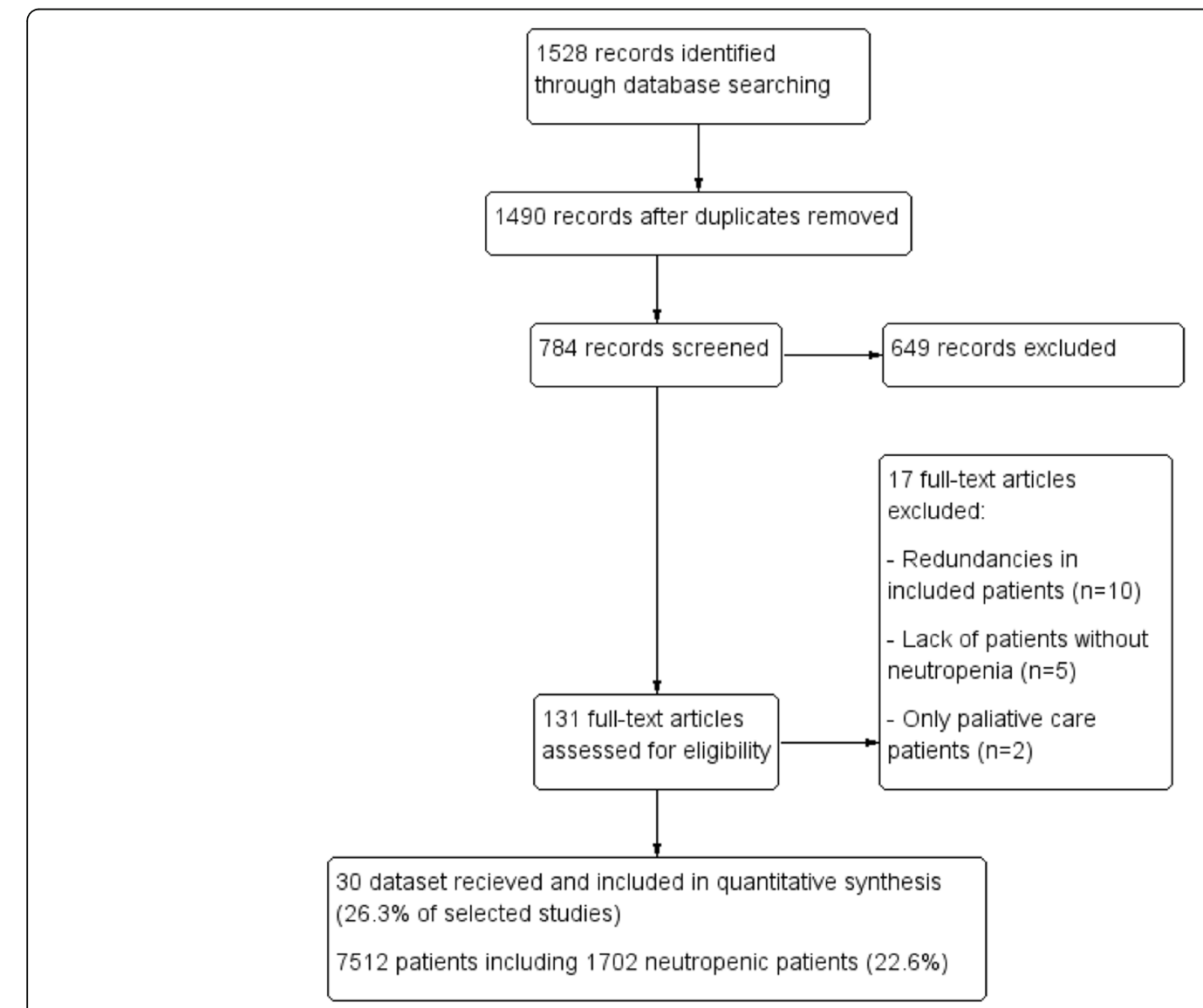

Fig. 1 Flow chart of study selection 


\section{Characteristics of included studies}

The included studies were published from 2006 to 2015 . Sixteen were prospective cohort studies (53\%) and six (20\%) were multicentric cohort studies (Table 1). The variable of outcome was hospital mortality in 27 studies and 28-day mortality in three studies. Overall, the number of patients included per study was 166 (IQR 99-266) and ranged from 34 [38] to 1090 [35].

\section{Characteristics of the patients}

Of the 7515 included patients, three were excluded due to missing major variables (neutropenia or mortality) leading to analysis of 7512 patients. Of these patients, 4943 were included in monocenter studies $(65.8 \%)$ and 5841 (77.8\%) in prospective studies (Table 2).

Median age was 60 years (49-69) and median SAPS II was $42(28-57)$ (Table 2). Overall, 3366 patients (44.8\%) had a solid tumor and 439 patients were allogeneic stem cell transplant recipients (5.8\%). Respectively, 3710 patients (49.4\%), 3084 patients (41.1\%) and 1201 patients (16\%) required invasive mechanical ventilation, vasopressors or renal replacement therapy.

\section{Outcome}

Unadjusted mortality in the studied population was $47.1 \%$ $(n=3538)$, including mortality of $60.2 \%(n=1025)$ and
43.2\% ( $n=2504)$ in neutropenic and non-neutropenic patients, respectively $(P<0.001)$.

After adjustment for confounders, and taking study effect into account, neutropenia was independently associated with mortality (OR 1.41; 95\% CI 1.23-1.62; $P=0.03$ ) (Table 3, Fig. 2).

\section{Influence of neutropenia in predefined subgroups}

When analyzed separately, neither admission period, underlying malignancy nor need for mechanical ventilation modified the influence of neutropenia on outcome (Additional file 1: Tables S1-S3).

In patients admitted after 2007 (median admission period; $n=3563$, including 880 neutropenic patients), neutropenia was independently associated with an increased mortality (OR 1.40; 95\% CI 1.16-1.70; $P<0.001$ ).

In patients with hematological malignancy $(n=4149$, including 1470 neutropenic patients), neutropenia was independently associated with an increased mortality (OR 1.30; 95\% CI 1.11-1.51; $P<0.001$ ).

Among the included patients, data on use of G-CSF was available for 1949 patients (25.9\%). Among the 788 patients receiving G-CSF, 587 were neutropenic. After adjustment for confounders (Additional file 1: Table S4), neutropenia was not independently associated with outcome (OR 1.03; 95\% CI 0.70-1.51; $P=0.90$ ).

Table 2 Patient characteristics

\begin{tabular}{|c|c|c|c|c|c|}
\hline Variable & $\begin{array}{l}\text { Missing data, } n \\
(\%)\end{array}$ & $\begin{array}{l}\text { Overall population }(n= \\
7515)\end{array}$ & $\begin{array}{l}\text { Neutropenic patients }(n= \\
1702)^{\mathrm{a}}\end{array}$ & $\begin{array}{l}\text { Non-neutropenic patients }(n= \\
5810)^{\mathrm{a}}\end{array}$ & $\begin{array}{l}P \\
\text { value }\end{array}$ \\
\hline Age (years) & $15(0.2 \%)$ & $60(49-69)$ & $55(41-64)$ & $61(51-70)$ & $\begin{array}{l}< \\
0.001\end{array}$ \\
\hline ICU admission year & 0 & 2007 (2004-2010) & 2008 (2005-2010) & 2007 (2004-2010) & $\begin{array}{l}< \\
0.001\end{array}$ \\
\hline \multicolumn{6}{|l|}{ Underlying malignancy } \\
\hline Solid tumors & $0(0 \%)$ & $3366(44.8 \%)$ & $232(13.6 \%)$ & $3131(53.9 \%)$ & $\begin{array}{l}< \\
0.001\end{array}$ \\
\hline $\begin{array}{l}\text { Hematological } \\
\text { malignancy }\end{array}$ & $0(0 \%)$ & $4149(55.2 \%)$ & $1470(86.4 \%)$ & $2679(46.1 \%)$ & $\begin{array}{l}< \\
0.001\end{array}$ \\
\hline Allogeneic HSCT & $0(0 \%)$ & $439(5.8 \%)$ & $186(10.9 \%)$ & $253(4.4 \%)$ & $\begin{array}{l}< \\
0.001\end{array}$ \\
\hline SAPS ॥ & $503(6.7 \%)$ & $41(28-57)$ & $51(34-68)$ & $39(26-54)$ & $\begin{array}{l}< \\
0.001\end{array}$ \\
\hline \multicolumn{6}{|c|}{ Organ support at ICU admission } \\
\hline Mechanical ventilation & $1(0 \%)$ & $3804(50.6 \%)$ & $964(56.6 \%)$ & $2839(48.9 \%)$ & $\begin{array}{l}< \\
0.001\end{array}$ \\
\hline Vasopressors & $0(0 \%)$ & $3084(41 \%)$ & $954(56.1 \%)$ & $2129(36.6 \%)$ & $\begin{array}{l}< \\
0.001\end{array}$ \\
\hline $\begin{array}{l}\text { Renal replacement } \\
\text { therapy }\end{array}$ & $58(0.8 \%)$ & $1201(16 \%)$ & $386(22.7 \%)$ & $815(14 \%)$ & $\begin{array}{l}< \\
0.001\end{array}$ \\
\hline Mortality & $2(0 \%)$ & $3538(47.1 \%)$ & $1021(60 \%)$ & $2517(43.3 \%)$ & $\begin{array}{l}< \\
0.001\end{array}$ \\
\hline
\end{tabular}


Table 3 Factors independently associated with mortality after adjustment for confounders (mix-linear model taking study effect into account)

\begin{tabular}{llll}
\hline Variable & Odds ratio & $95 \% \mathrm{Cl}$ & $P$ value \\
\hline Neutropenia & 1.41 & $1.23-1.62$ & 0.03 \\
Age $<50$ years & Reference & - & - \\
Age 50-59 years & 1.11 & $0.95-1.28$ & 0.18 \\
Age 60-69 years & 1.32 & $1.13-1.53$ & $<0.001$ \\
Age 69+ years & 1.66 & $1.43-1.94$ & $<0.001$ \\
Solid tumors (vs HM) & 0.69 & $0.58-0.81$ & $<0.001$ \\
Allogeneic HSCT & 1.91 & $1.50-2.43$ & $<0.001$ \\
Mechanical ventilation & 3.01 & $2.66-3.41$ & $<0.001$ \\
Vasopressors & 2.07 & $1.83-2.35$ & $<0.001$ \\
Renal replacement therapy & 1.50 & $1.29-1.75$ & $<0.001$ \\
\hline
\end{tabular}

$\mathrm{Cl}$ confidence interval, HM hematological malignancy, HSCT hematopoietic stem cell transplantation

\section{Discussion}

This large dataset resulting from systematic review of individual data confirms neutropenia to be independently associated with mortality in critically ill cancer patients. According to our results, the prognostic impact of neutropenia was unchanged when stratifying for malignancy, period of ICU admission or use of mechanical ventilation. However, in patients treated with G-CSF, neutropenia was no longer associated with mortality, suggesting that the use of G-CSF may influence the prognostic impact of neutropenia in this setting.

Neutropenia remains an accepted side effect of most treatments administered to hematological patients [52]. Neutropenia is associated with complications that include severe sepsis [53], acute respiratory failure [54] and specific conditions such as neutropenic enterocolitis [55]. Although these side effects are likely to influence the outcome of critically ill patients, results of studies in this field remain controversial. Although neutropenia remains associated with a poor outcome in general ICU populations [16], several recent studies failed to demonstrate an impact of neutropenia on the outcome of

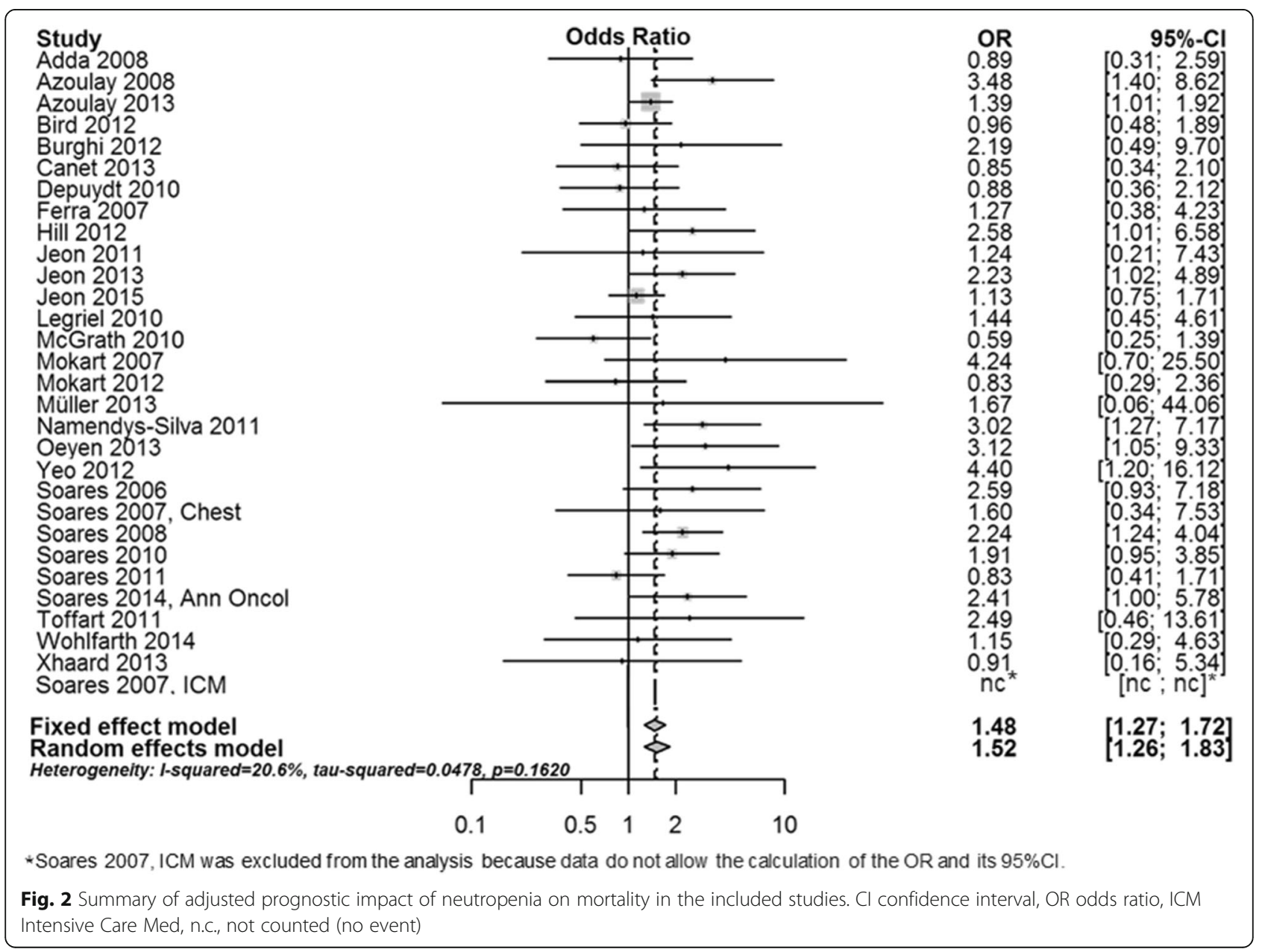


critically ill cancer patients $[8,12]$. The numerous mechanisms of immune deficiency in these patients, along with the prognostic influence of disease severity or need for organ support therapies, might explain these negative findings. A previous systematic review, based on aggregated data, suggested that neutropenia was associated with a $10 \%$ increase in overall mortality but the result may have been confounded by studies with negative findings due to lack of statistical power [17]. In fact, the influence of neutropenia was no longer significant after adjusting for confounders but in a limited study population [17]. Results of our study confirm that, even after adjustment for confounders, neutropenia is associated with a poor outcome. These data strongly suggest that neutropenia, conversely to the recently published recommendations [15], should be considered a prognostic factor. Additional studies are needed to confirm our results and to identify room for improvements in the management of this specific population.

In most of the predefined subgroups, namely according to underlying malignancy, use of mechanical ventilation or according to ICU admission period, the impact of neutropenia on outcome was unchanged. However, it must be noted that the impact of neutropenia was no longer associated with outcome in patients treated with G-CSF. Prophylactic use of G-CSF in patients with hematological malignancy or solid tumors has proven efficacy in decreasing the risk or duration of neutropenia, in limiting the risk of infectious disease and in specific settings decreasing both overall mortality and infection-related mortality [56, 57]. Conversely, use of G-CSF in patients with already overt infections (curative G-CSF) was found to have a limited benefit in neutropenic patients [58, 59]. Data regarding interest of prophylactic or curative use of G-CSF are limited to studies with high risk of bias and suggest a limited efficacy in this setting [60-62]. In addition, G-CSF remains associated with potential side effects, including risk of worsening respiratory status during neutropenia recovery [63]. Our study is the first to date to suggest indirectly that G-CSF may limit the prognostic impact of neutropenia in critically ill patients. Although this result is insufficient to modify existing recommendations, additional interventional studies in this setting may be warranted.

This study has several important limitations. Firstly, despite the biological plausibility, this study at best demonstrated a statistical association between neutropenia and mortality. Whether this statistical association may be due to a causal relationship remains to be demonstrated. Secondly, the observed dependent association that might have been affected by allocation bias not taken into account by our analysis. In line with this, available data did not allow adjustment for center or volume effect, assessment of the impact of organizational processes [64], influence of duration of neutropenia or influence of several management strategies including impact of antifungal prophylaxis. Last, only a quarter of identified studies were ultimately included. However, it must be noted that the large dataset, and the analysis adjusting for study influence and modeling of unrecorded data by using a mixed effect model, should have, at least partly, taken these effects into account. In line with this, several arbitrary choices were made during analysis as regards the study inclusion period or cutoff point to define the ICU admission period. The lack of other reliable cutoff points, however, is to be noted when taking into account these limits. Last, the influence of G-CSF was assessed only indirectly, in a subset of patients in whom the use of G-CSF was recorded, without information regarding the rational for its prescription. Thus, our negative results might reflect either a lack of statistical power or an inclusion bias. Nevertheless, our results are a strong plea for further interventional studies to assess the influence of G-CSF in critically ill patients with neutropenia.

\section{Conclusion}

This systematic review, comprising 7515 patients, suggests a meaningful survival in neutropenic critically ill patients despite an independent association with poor outcome. Neither underlying malignancy, a period of admission nor use of mechanical ventilation significantly modified this result. Interestingly, neutropenia was no longer significantly associated with outcome in patients treated with G-CSF. Thus, our results may suggest a beneficial effect of G-CSF in critically ill cancer patients and serve as a plea for additional studies in this field.

\section{Key messages}

- This systematic review of individual data suggests a meaningful survival in neutropenic critically ill patients despite an independent association with poor outcome.

- Neutropenia is no longer significantly associated with outcome in patients treated with G-CSF, suggesting a beneficial effect of this therapy in critically ill cancer patients.

- The independent association of neutropenia with poor outcome suggest additional research to be required in way to limit excess of mortality in this subgroup of critically-ill patients.

- Potential beneficial effect of G-CSF in critically-ill neutropenic patients is a plea for additional studies assessing benefits of therapeutic G-CSF in this subgroup of patients. 


\section{Additional file}

Additional file 1: Table S1. Factors independently associated with mortality after adjustment for confounders among patients with ICU admission after 2007 (mix-linear model taking study effect into account). Table S2. Factors independently associated with mortality after adjustment for confounders among patients with hematological malignancy (mix-linear model taking study effect into account). Table S3. Factors independently associated with mortality after adjustment for confounders among patients requiring mechanical ventilation (mix-linear model taking study effect into account). Table S4. Factors independently associated with mortality after adjustment for confounders among patients receiving G-CSF (mix-linear model taking study effect into account) (DOC $58 \mathrm{~kb}$ )

\section{Abbreviations}

APACHE: Acute Physiology and Chronic Health Evaluation; G-

CSF: Granulocyte colony stimulating factor; HSCT: Hematopoietic stem cell transplant; ICU: Intensive care unit; SAPS: Simplified Acute Physiology Score

\section{Acknowledgements}

The authors thank Sophie Perinel and Marie Bouteloup for their invaluable help with this study.

The authors thank the patients who accepted to participate studies included in this systematic review and the health care providers involved in these studies.

\section{Authors' contributions}

QG and EA participated in acquisition of data, interpretation of data, drafting of the manuscript and critical revision of the manuscript. DM participated in study design, interpretation of data and critical revision of the manuscript. MS, KJ, SO, CKR, PG, MO, QAH, PD, CF, A-CT, PS, AM and VL participated in acquisition of data, interpretation of data, drafting of the manuscript and critical revision of the manuscript. FT and $A B$ participated in statistical analysis, interpretation of data, drafting of the manuscript and critical revision of the manuscript. MD conceived the study, participated in study design and coordination, acquisition of data, statistical analysis and interpretation of data, drafting of the manuscript and critical revision of the manuscript. MD had full access to all of the data in the study and takes responsibility for the integrity of the data and the accuracy of the data analysis. All authors read and approved the final manuscript. MD affirms that the manuscript is an honest, accurate and transparent account of the study being reported; that no important aspects of the study have been omitted; and that any discrepancies from the study as registered have been explained.

\section{Ethics approval and consent to participate}

Each of the included studies obtained approval of a local or a national ethic committee in accordance with local legislation. Patients or their next of kin consented to participate or were informed of the included study and did not oppose participation according to local legislation. With regard to its retrospective design and lack of change of the primary outcome variable, the need for additional ethic committee approval was waived according to French Law.

\section{Competing interests}

MD reports having received consulting fees from Sanofi. QAH declares having received travel support from Amgen. The remaining authors declare that they have no competing interests related to this study.

\section{Publisher's Note}

Springer Nature remains neutral with regard to jurisdictional claims in published maps and institutional affiliations.

\section{Author details}

${ }^{1}$ Medical-Surgical ICU, Saint-Etienne University Hospital, Avenue Albert Raimond, 42270 Saint-Priest-en-Jarez, France. ${ }^{2}$ Jacques Lisfranc Saint-Etienne Medical School, Jean Monnet University, Saint-Priest-en-Jarez, France. ${ }^{3}$ Medical ICU, Saint-Louis University Hospital, AP-HP, Paris, France. ${ }^{4}$ Sorbonne-Paris-Cité, Medical School, Paris-Diderot University, Paris, France.
${ }^{5}$ Anesthesiology and Intensive Care Unit, Institut Paoli Calmette, Marseille, France. ${ }^{6}$ Department of Critical Care and Graduate Program in Translational Medicine, D'Or Institute for Research and Education, Rio de Janeiro, Brazil. ${ }^{7}$ Department of Critical Care Medicine, Samsung Medical Center, Sungkyunkwan University School of Medicine, Seoul, South Korea. ${ }^{8}$ Department of Intensive Care Medicine, Ghent University Hospital, Ghent, Belgium. ${ }^{9}$ Division of Pulmonary and Critical Care Medicine, Department of Internal Medicine, The Catholic University of Korea, Seoul, Korea.

${ }^{10}$ Department of Critical Care, The Royal Marsden Hospital, Fulham Road, London SW3 6JJ, UK. ${ }^{11}$ Department of Critical Care \& Nephrology, Guy's \& St Thomas' NHS Foundation Hospital, Westminster Bridge Road, London, UK.

${ }^{12}$ Department of Haematology, Leeds Teaching Hospitals, Leeds, UK. ${ }^{13}$ Department of Clinical Hematology, ICO-Hospital Germans Trias i Pujol, Josep Carreras Research Institute, Universitat Autònoma de Barcelona, Badalona, Spain. ${ }^{14}$ Thoracic Oncology Unit, Grenoble Alpes University Hospital, Grenoble, France. ${ }^{15}$ Department of Medicine I, Intensive Care Unit 13i2, Comprehensive Cancer Center, Medical University of Vienna, Vienna, Austria. ${ }^{16}$ Universidade Federal do Rio Grande do Sul, Porto Alegre, Rio Grande do Sul, Brazil. ${ }^{17}$ Hygée Centre and Public Health Department, Lucien Neuwirth Cancerology Institute, Saint-Priest-en-Jarez, France. ${ }^{18}$ INSERM, ECSTRRA team, UMR 1153, Paris, France.

Received: 18 December 2017 Accepted: 21 May 2018

Published online: 04 December 2018

\section{References}

1. GBD 2015 Mortality and Causes of Death Collaborators. Global, regional, and national life expectancy, all-cause mortality, and cause-specific mortality for 249 causes of death, 1980-2015: a systematic analysis for the Global Burden of Disease Study 2015. Lancet. 2016;388:1459-544.

2. Ferlay J, Soerjomataram I, Dikshit R, Eser S, Mathers C, Rebelo M, et al. Cancer incidence and mortality worldwide: sources, methods and major patterns in GLOBOCAN 2012. Int J Cancer. 2015;136:E359-86.

3. Vento S, Cainelli F, Temesgen Z. Lung infections after cancer chemotherapy. Lancet Oncol. 2008:9:982-92.

4. Morgan C, Tillett T, Braybrooke J, Ajithkumar T. Management of uncommon chemotherapy-induced emergencies. Lancet Oncol. 2011;12:806-14.

5. Castaigne S, Pautas C, Terré C, Raffoux E, Bordessoule D, Bastie J-N, et al. Effect of gemtuzumab ozogamicin on survival of adult patients with denovo acute myeloid leukaemia (ALFA-0701): a randomised, open-label, phase 3 study. Lancet. 2012;379:1508-16.

6. Azoulay $E$, Pène $F$, Darmon $M$, Lengliné $E$, Benoit $D$, Soares $M$, et al. Managing critically ill hematology patients: time to think differently. Blood Rev. 2015;29:359-67.

7. Mokart D, Pastores SM, Darmon M. Has survival increased in cancer patients admitted to the ICU? Yes. Intensive Care Med. 2014;40:1570-2.

8. Azoulay E, Mokart D, Pène F, Lambert J, Kouatchet A, Mayaux J, et al. Outcomes of critically ill patients with hematologic malignancies: prospective multicenter data from France and Belgium - a groupe de recherche respiratoire en reanimation onco-hematologique study. J Clin Oncol. 2013;31:2810-8.

9. Peigne V, Rusinová K, Karlin L, Darmon M, Fermand J-P, Schlemmer B, et al. Continued survival gains in recent years among critically ill myeloma patients. Intensive Care Med. 2009;35:512-8.

10. Zuber B, Tran T-C, Aegerter P, Grimaldi D, Charpentier J, Guidet B, et al. Impact of case volume on survival of septic shock in patients with malignancies. Crit Care Med. 2012;40:55-62.

11. Mokart D, Darmon M, Resche-Rigon M, Lemiale V, Pène F, Mayaux J, et al. Prognosis of neutropenic patients admitted to the intensive care unit. Intensive Care Med. 2015:41:296-303.

12. Azoulay $E$, Lemiale $V$, Mokart $D$, Pène $F$, Kouatchet $A$, Perez $P$, et al. Acute respiratory distress syndrome in patients with malignancies. Intensive Care Med. 2014:40:1106-14.

13. Puig N, De La Rubia J, Jarque I, Salavert M, Moscardó F, Sanz J, et al. Characteristics of and risk factors for pneumonia in patients with hematological malignancies developing fever after autologous blood stem cell transplantation. Leuk Lymphoma. 2007:48:2367-74.

14. Rhee CK, Kang JY, Kim YH, Kim JW, Yoon HK, Kim SC, et al. Risk factors for acute respiratory distress syndrome during neutropenia recovery in patients with hematologic malignancies. Crit Care. 2009;13:R173. 
15. Schnell D, Azoulay E, Benoit D, Clouzeau B, Demaret P, Ducassou S, et al. Management of neutropenic patients in the intensive care unit (NEWBORNS EXCLUDED) recommendations from an expert panel from the French Intensive Care Society (SRLF) with the French Group for Pediatric Intensive Care Emergencies (GFRUP), the French Society of Anesthesia and Intensive Care (SFAR), the French Society of Hematology (SFH), the French Society for Hospital Hygiene (SF2H), and the French infectious diseases society (SPILF). Ann Intensive Care. 2016;6:90.

16. Tolsma V, Schwebel C, Azoulay E, Darmon M, Souweine B, Vesin A, et al. Sepsis severe or septic shock: outcome according to immune status and immunodeficiency profile. Chest. 2014;146:1205-13.

17. Bouteloup M, Perinel S, Bourmaud A, Azoulay E, Mokart D, Darmon M, et al. Outcomes in adult critically ill cancer patients with and without neutropenia: a systematic review and meta-analysis of the Groupe de Recherche en Réanimation Respiratoire du patient d'Onco-Hématologie (GRRR-OH). Oncotarget. 2017:8:1860-70.

18. Devillé $W L$, Buntinx F, Bouter LM, Montori VM, de Vet HCW, van der Windt DAWM, et al. Conducting systematic reviews of diagnostic studies: didactic guidelines. BMC Med Res Methodol. 2002;2:9.

19. Vasilevskis EE, Kuzniewicz MW, Dean ML, Clay T, Vittinghoff E, Rennie DJ, et al. Relationship between discharge practices and intensive care unit inhospital mortality performance: evidence of a discharge Bias. Med Care. 2009;47:803-12.

20. Kaukonen K-M, Bailey M, Pilcher D, Cooper DJ, Bellomo R. Systemic inflammatory response syndrome criteria in defining severe sepsis. N Engl J Med. 2015;372:1629-38.

21. Shimabukuro-Vornhagen A, Böll B, Kochanek M, Azoulay É, von Bergwelt-Baildon MS. Critical care of patients with cancer. CA Cancer J Clin. 2016;66:496-517.

22. Schneider AG, Lipcsey M, Bailey M, Pilcher DV, Bellomo R. Simple translational equations to compare illness severity scores in intensive care trials. J Crit Care. 2013;28:885.e1-8.

23. Soares M, Salluh JIF, Carvalho MS, Darmon M, Rocco JR, Spector N. Prognosis of critically ill patients with cancer and acute renal dysfunction. J Clin Oncol. 2006:24:4003-10.

24. Mokart D, Sannini A, Brun J-P, Faucher M, Blaise D, Blache J-L, et al. Nterminal pro-brain natriuretic peptide as an early prognostic factor in cancer patients developing septic shock. Crit Care. 2007;11:R37.

25. Azoulay E, Mokart D, Rabbat A, Pene F, Kouatchet A, Bruneel F, et al. Diagnostic bronchoscopy in hematology and oncology patients with acute respiratory failure: prospective multicenter data. Crit Care Med. 2008;36:100-7.

26. Legriel S, Marijon H, Darmon M, Lemiale V, Bedos J-P, Schlemmer B, et al. Central neurological complications in critically ill patients with malignancies. Intensive Care Med. 2010;36:232-40

27. McGrath S, Chatterjee F, Whiteley C, Ostermann M. ICU and 6-month outcome of oncology patients in the intensive care unit. QJM. 2010;103:397-403.

28. Soares M, Caruso P, Silva E, Teles JMM, Lobo SMA, Friedman G, et al. Characteristics and outcomes of patients with cancer requiring admission to intensive care units: a prospective multicenter study. Crit Care Med. 2010;38:9-15.

29. Song J-U, Suh GY, Chung MP, Kim H, Kwon OJ, Jung CW, et al. Risk factors to predict outcome in critically ill cancer patients receiving chemotherapy in the intensive care unit. Support Care Cancer. 2011;19:491-5.

30. Bird GT, Farquhar-Smith P, Wigmore T, Potter M, Gruber PC. Outcomes and prognostic factors in patients with haematological malignancy admitted to a specialist cancer intensive care unit: a $5 \mathrm{yr}$ study. $\mathrm{Br} \mathrm{J}$ Anaesth. 2012;108:452-9.

31. Hill QA, Kelly RJ, Patalappa C, Whittle AM, Scally AJ, Hughes A, et al. Survival of patients with hematological malignancy admitted to the intensive care unit: prognostic factors and outcome compared to unselected medical intensive care unit admissions, a parallel group study. Leuk Lymphoma. 2012;53:282-8

32. Xhaard A, Epelboin L, Schnell D, Vincent F, Levy V, Malphettes M, et al Outcomes in critically ill chronic lymphocytic leukemia patients. Support Care Cancer. 2013;21:1885-91.

33. Namendys-Silva SA, González-Herrera MO, García-Guillén FJ, TexcocanoBecerra J, Herrera-Gómez A. Outcome of critically ill patients with hematological malignancies. Ann Hematol. 2012;92:699-705.

34. Wohlfarth P, Staudinger T, Sperr WR, Bojic A, Robak O, Hermann A, et al. Prognostic factors, long-term survival, and outcome of cancer patients receiving chemotherapy in the intensive care unit. Ann Hematol. 2014;93:1629-36.
35. Soares M, Salluh JIF, Torres VBL, Leal JVR, Spector N. Short- and long-term outcomes of critically ill patients with cancer and prolonged ICU length of stay. Chest. 2008;134:520-6.

36. Depuydt PO, Benoit DD, Roosens CD, Offner FC, Noens LA, Decruyenaere JM. The impact of the initial ventilatory strategy on survival in hematological patients with acute hypoxemic respiratory failure. J Crit Care. 2010;25:30-6.

37. Canet E, Zafrani L, Lambert J, Thieblemont C, Galicier L, Schnell D, et al. Acute kidney injury in patients with newly diagnosed high-grade hematological malignancies: impact on remission and survival. PLoS One. 2013;8:e55870.

38. Müller AM, Gazzana MB, Silva DR. Outcomes for patients with lung cancer admitted to intensive care units. Rev Bras Ter Intensiva. 2013;25:12-6.

39. Oeyen SG, Benoit DD, Annemans L, Depuydt PO, Van Belle SJ, Troisi Rl, et al. Long-term outcomes and quality of life in critically ill patients with hematological or solid malignancies: a single center study. Intensive Care Med. 2013;39:889-98.

40. Ferrà $C$, Marcos $P$, Misis $M$, Morgades $M$, Bordejé $M-L$, Oriol $A$, et al. Outcome and prognostic factors in patients with hematologic malignancies admitted to the intensive care unit: a single-center experience. Int J Hematol. 2007:85:195-202.

41. Soares M, Darmon M, Salluh JIF, Ferreira CG, Thiéry G, Schlemmer B, et al. Prognosis of lung cancer patients with life-threatening complications. Chest. 2007;131:840-6.

42. Toffart A-C, Minet C, Raynard B, Schwebel C, Hamidfar-Roy R, Diab S, et al. Use of intensive care in patients with nonresectable lung cancer. Chest. 2011;139:101-8

43. Burghi $G$, Lemiale V, Seguin A, Lambert J, Lacroix C, Canet E, et al. Outcomes of mechanically ventilated hematology patients with invasive pulmonary aspergillosis. Intensive Care Med. 2011;37:1605-12.

44. Adda M, Coquet I, Darmon M, Thiery G, Schlemmer B, Azoulay E. Predictors of noninvasive ventilation failure in patients with hematologic malignancy and acute respiratory failure. Crit Care Med. 2008;36:2766-72.

45. Yoo H, Suh GY, Jeong B-H, Lim SY, Chung MP, Kwon OJ, et al. Etiologies, diagnostic strategies, and outcomes of diffuse pulmonary infiltrates causing acute respiratory failure in cancer patients: a retrospective observational study. Crit Care. 2013;17:R150.

46. Lee D-S, Suh GY, Ryu J-A, Chung CR, Yang JH, Park C-M, et al. Effect of early intervention on long-term outcomes of critically ill cancer patients admitted to ICUs. Crit Care Med. 2015;43:1439-48.

47. Soares M, Salluh JIF, Toscano L, Dias FL. Outcomes and prognostic factors in patients with head and neck cancer and severe acute illnesses. Intensive Care Med. 2007;33:2009-13.

48. Souza-Dantas VC, Salluh JIF, Soares M. Impact of neutropenia on the outcomes of critically ill patients with cancer: a matched case-control study. Ann Oncol. 2011;22:2094-100.

49. Soares M, Toffart A-C, Timsit J-F, Burghi G, Irrazábal C, Pattison N, et al. Intensive care in patients with lung cancer: a multinational study. Ann Oncol. 2014;25:1829-35.

50. Mokart D, Etienne A, Esterni B, Brun J-P, Chow-Chine L, Sannini A, et al. Critically ill cancer patients in the intensive care unit: short-term outcome and 1-year mortality. Acta Anaesthesiol Scand. 2012;56:178-89.

51. Yeo CD, Kim JW, Kim SC, Kim YK, Kim KH, Kim HJ, et al. Prognostic factors in critically ill patients with hematologic malignancies admitted to the intensive care unit. J Crit Care. 2012;27:739.e1-6.

52. Maschmeyer G, Beinert $T$, Buchheidt $D$, Cornely OA, Einsele $H$, Heinz W, et al. Diagnosis and antimicrobial therapy of lung infiltrates in febrile neutropenic patients: guidelines of the infectious diseases working party of the German Society of Haematology and Oncology. Eur J Cancer. 2009:45:2462-72.

53. Legrand M, Max A, Peigne V, Mariotte E, Canet E, Debrumetz A, et al. Survival in neutropenic patients with severe sepsis or septic shock. Crit Care Med. 2012:40:43-9.

54. Mokart D, van Craenenbroeck T, Lambert J, Textoris J, Brun J-P, Sannini A, et al. Prognosis of acute respiratory distress syndrome in neutropenic cancer patients. Eur Respir J. 2012;40:169-76.

55. Hohenberger $P$, Buchheidt D. Surgical interventions in patients with hematologic malignancies. Crit Rev Oncol Hematol. 2005;55:83-91.

56. Kuderer NM, Dale DC, Crawford J, Lyman GH. Impact of primary prophylaxis with granulocyte colony-stimulating factor on febrile neutropenia and mortality in adult cancer patients receiving chemotherapy: a systematic review. J Clin Oncol. 2007;25:3158-67. 
57. Lyman GH, Dale DC, Culakova E, Poniewierski MS, Wolff DA, Kuderer $\mathrm{NM}$, et al. The impact of the granulocyte colony-stimulating factor on chemotherapy dose intensity and cancer survival: a systematic review and meta-analysis of randomized controlled trials. Ann Oncol. 2013;24:2475-84.

58. Clark OAC, Lyman GH, Castro AA, Clark LGO, Djulbegovic B. Colonystimulating factors for chemotherapy-induced febrile neutropenia: a meta-analysis of randomized controlled trials. J Clin Oncol. 2005;23: 4198-214.

59. Mhaskar R, Clark OAC, Lyman G, Engel Ayer Botrel T, Morganti Paladini L, Djulbegovic B. Colony-stimulating factors for chemotherapy-induced febrile neutropenia. Cochrane Database Syst Rev. 2014;(10):CD003039.

60. Bouchama A, Khan B, Djazmati W, Shukri K. Hematopoietic colonystimulating factors for neutropenic patients in the ICU. Intensive Care Med. 1999;25:1003-5.

61. Gruson D, Hilbert G, Vargas F, Valentino R, Chene G, Boiron JM, et al. Impact of colony-stimulating factor therapy on clinical outcome and frequency rate of nosocomial infections in intensive care unit neutropenic patients. Crit Care Med. 2000;28:3155-60.

62. Darmon M, Azoulay E, Alberti C, Fieux F, Moreau D, Le Gall J-R, et al. Impact of neutropenia duration on short-term mortality in neutropenic critically ill cancer patients. Intensive Care Med. 2002;28:1775-80.

63. Karlin L, Darmon M, Thiéry G, Ciroldi M, de Miranda S, Lefebvre A, et al. Respiratory status deterioration during G-CSF-induced neutropenia recovery Bone Marrow Transplant. 2005:36:245-50.

64. Soares M, Bozza FA, Azevedo LCP, Silva UVA, Corrêa TD, Colombari F, et al. Effects of organizational characteristics on outcomes and resource use in patients with cancer admitted to intensive care units. J Clin Oncol. 2016;34:3315-24.

\section{Ready to submit your research? Choose BMC and benefit from:}

- fast, convenient online submission

- thorough peer review by experienced researchers in your field

- rapid publication on acceptance

- support for research data, including large and complex data types

- gold Open Access which fosters wider collaboration and increased citations

- maximum visibility for your research: over $100 \mathrm{M}$ website views per year 